\title{
Game Analysis of Price Competition between Three Echelon Supply Chains
}

\author{
Min Tan, Yaxiang Liu* \\ Northwest A\&F University, Xianyang, China \\ Email: *oklyx@nwsuaf.edu.cn
}

How to cite this paper: Tan, M. and Liu, Y.X. (2018) Game Analysis of Price Competition between Three Echelon Supply Chains. American Journal of Industrial and Business Management, 8, 2403-2420. https://doi.org/10.4236/ajibm.2018.812161

Received: December 5, 2018

Accepted: December 26, 2018

Published: December 29, 2018

Copyright $\odot 2018$ by author(s) and Scientific Research Publishing Inc. This work is licensed under the Creative Commons Attribution International License (CC BY 4.0).

http://creativecommons.org/licenses/by/4.0/

(c) (i) Open Access

\begin{abstract}
Aiming at the new problem of price competition between three echelon supply chains, this paper quantitatively analyzes the reasons for the low price competition under the ten decision-making forms under the framework of the Bertrand game, and then one of the supply chains is differentiated by providing value-added services, thus reducing the impact of price competition on them. It also deduces whether the critical point of differential investment is to be differentiated, and compares the value increment of the ten decision forms. The conclusion is: when the product differentiation is the same, the value of the supply chain of value-added services depends on the decision form of the other chain, and the decentralized decision making is the best form of decision. In particular, when the degree of alienation is relatively large, the difference between the value of three differentiated investment critical points is 2 times.
\end{abstract}

\section{Keywords}

Three Echelon Supply Chain, Price Competition, Bertrand Game, Value-Added Service, Differentiation

\section{Introduction}

Since the reform and opening up, China's economy has developed rapidly, and all walks of life have shown a prosperous scene under the market economy. From the perspective of China's market structure, products in many industries have shown the characteristics of monopolistic competition and oligopoly. Along with the emergence of oligopolistic enterprises, the phenomenon of "price war" has also appeared widely. For this reason, enterprises adopt differentiated strategies to carry out production and operation to ensure the sustainable and stable development of enterprises. Lu Wenlong [1] and others applied the Hotel- 
ling model to the selection of product attributes of enterprises in international trade, and analyzed the impact of trade on horizontal differentiation of products in two trade markets. Because consumers not only consider commodity prices when considering goods, but also consider the demand market for commodity quality levels (Gong Richao [2] and so on). Studies have shown that in order to achieve Nash equilibrium, the two companies must adopt certain differentiation strategies. Moreover, in a balanced state, if the market is a price-sensitive market, the degree of differentiation of the enterprise is about to be more favorable to both enterprises and consumers. Li Baixun [3] takes two single-chain supply chains including one manufacturer and one retailer as the research object. Under the Bertrand game framework, explore three different decision structures between the two supply chains, indicating the price and service between supply chains. When the competition intensity is low, the centralized decision is the Pareto equilibrium solution of the game between supply chains. However, when the competition intensity is high, the centralized decision will cause the two supply chains to fall into the "prisoner's dilemma". Tan Zhanglu [4] based on the Bertrand model with price as the decision variable, establishes a dynamic repeated game model of multi-oligomer coal enterprises, studies the dynamic game process under different target strategies, and analyzes the impact of competition strategy behaviors on coal prices among coal enterprises. Peng Lang [5] considers sales channels including electronic channels and retail channels, and uses game theory to study the impact of manufacturers and retailers' services on channel prices. The study found that when the service level of the manufacturer is below a certain threshold, it increases. The price favors the price increase of electronic channels and forces retailers to lower the price of retail channels. Li Baixun [6] takes two supply chain selection strategies as the research object, analyzes the influence of risk avoidance degree, inter-chain game order and market competition intensity on channel selection equilibrium strategy under the conditions of Stackelberg game and Bertrand game between chains.

The influence of supply chain product differentiation behavior on price equilibrium solution has been widely concerned. The above research results are mainly limited to the two-level supply chain, and rarely involve the three-level supply chain. In this paper, the three level supply chain consisting of suppliers, manufacturers and retailers is taken as the research object. This assumption is more in line with the actual situation. This paper starts with the differentiation of three-level supply chain products and introduces a differentiated model to study how the supply chain can realize product differentiation through value-added services.

\section{The Model Description}

In the multi-supply chain competition environment, there are two levels of game, one is the game between supply chains. This paper assumes that the two supply chains are in the same position, that is, the Bertrand game between chains. On 
the other hand, the chain is a complete information dynamic game. Each supply chain has four combinations [7], and 1) indicates that suppliers, manufacturers, and retailers decentralized decisions; 2 ) indicates that suppliers and manufacturers make centralized decisions, while manufacturers and retailers decentralize decisions; 3) indicates that suppliers and manufacturers decentralize decisions while manufacturers and retailers focus on decision making. 4) indicates that suppliers, manufacturers and retailers make centralized decisions. In this paper, this combination form of $(m, n)$ is used to indicate that one supply chain uses the decision mode of $m$, and the other supply chain adopts the decision mode of $n$. There are ten combinations of the game problems in the two supply chains.

The Bertrand model is an oligopolistic price competition model. Its model assumes: 1) competition between supply chains by selecting prices; 2) products produced by the two supply chains are homogeneous, and 3) there is no formality between supply chains or informal conspiracy.

$c_{1}$ represents the total cost of a product in the supply chain, and $c_{2}$ represents the total cost of the supply chain two products, and does not consider other costs.

$p_{S_{i}}^{(m, n)}$ represents the supplier's pricing to the manufacturer in the supply chain $i$ in the $(m, n)$ decision mode, referred to as the supply price;

$p_{M_{i}}^{(m, n)}$ represents the pricing of the supply chain $i$ sold by the manufacturer to the retailer under decision mode $(m, n)$, referred to as the wholesale price;

$p_{R_{i}}^{(m, n)}$ represents the retail price of supply chain $i$ under decision mode $(m, n)$;

$\pi_{R_{i}}^{(m, n)}$ represents the profit of the retailer of supply chain $i$ under decision mode $(m, n)$;

$\pi_{M_{i}}^{(m, n)}$ represents the profit of the manufacturer of supply chain $i$ under decision mode $(m, n)$;

$\pi_{S_{i}}^{(m, n)}$ represents the profit of the supplier of supply chain $i$ under decision mode $(m, n)$;

$\pi_{i}^{(m, n)}$ Represents total profit in the supply chain decision model.

The production capacity and supply volume of the upstream enterprises are the same as those of the downstream enterprises. The demand function is as follows:

$$
q_{i}=1-p_{i}+\theta p_{3-i}, i=1,2 .
$$

where $q_{i}$ and $p_{i}$ are the product demand and retail price of supply chain $i ; \theta$ indicates the degree of product differentiation between supply chains respectively; $\theta=0$ indicates that the product differentiation between the two supply chains is maximized; $\theta=1$ means that the products in the two supply chains are the most homogenized.

\section{Establish and Solve Differential Models}

Scenario 1: The profit function of the supply chain system under decision can be 
expressed as

$$
\begin{gathered}
\max _{p_{R_{i}}^{(1,1)}>0} \pi_{R_{i}}^{(1,1)}=\left(p_{R_{i}}^{(1,1)}-p_{M_{i}}^{(1,1)}\right)\left(1-p_{R_{i}}^{(1,1)}+\theta p_{R_{3-i}}^{(1,1)}\right), i=1,2 . \\
\max _{p_{M_{i}}^{(1,1)}>0} \pi_{M_{i}}^{(1,1)}=\left(p_{M_{i}}^{(1,1)}-p_{S_{i}}^{(1,1)}\right)\left(q_{1}^{(1,1)}\left(p_{R_{i}}^{(1,1)}\right)\right), i=1,2 . \\
\pi_{S_{i}}^{(1,1)}=\left(p_{S_{i}}^{(1,1)}-c_{i}\right) q_{i}^{(1,1)}\left(p_{M_{i}}^{(1,1)}\right), i=1,2 .
\end{gathered}
$$

Theorem 1: Under the $(1,1)$ combination, the equilibrium solutions of the two supply chain retail prices are:

$$
\begin{aligned}
& p_{R_{i}}^{(1,1)}=\frac{\left(4-\theta^{2}\right)\left[4\left(2-\theta^{2}\right)^{2}-\theta^{2}\right]\left\{4\left[2\left(2-\theta^{2}\right)^{2}-\theta^{2}\right]^{2}-\theta^{2}\left(\theta^{2}-2\right)^{2}\right\}}{\times\left\{2\left(\theta^{2}-2\right)\left[2\left(\theta^{2}-2\right)^{2}-\theta^{2}\right]\left[8\left(\theta^{2}-2\right)^{3}-3 \theta^{2}\left(\theta^{2}-1\right)\left(\theta^{2}-2\right)+\theta^{4}\right] c_{1}\right.} \\
& +\theta\left(\theta^{2}-2\right)\left[2\left(\theta^{2}-2\right)^{2}-\theta^{2}\right]\left[8\left(\theta^{2}-2\right)^{3}-12\left(\theta^{2}-2\right)^{2}-3 \theta^{2}\left(\theta^{2}-2\right)+4 \theta^{2}\right] c_{2}\left(\mathrm{~d}_{1}\right) \\
& +(\theta+2)\left[2\left(\theta^{2}-2\right)-\theta\right]\left\{2\left[2\left(\theta^{2}-2\right)^{2}-\theta^{2}\right]-\theta\left(\theta^{2}-2\right)\right\} \\
& \left.\times\left\{4\left(\theta^{2}-3\right)\left[2\left(\theta^{2}-2\right)^{2}-\theta^{2}\right]-4\left(\theta^{2}-2\right)^{2}+\theta^{2}\left(\theta^{2}-2\right)\right\}\right\} \\
& p_{R_{2}}^{(1,1)}=\frac{\left(4-\theta^{2}\right)\left[4\left(\theta^{2}-2\right)^{2}-\theta^{2}\right]\left\{4\left[2\left(\theta^{2}-2\right)^{2}-\theta^{2}\right]^{2}-\theta^{2}\left(\theta^{2}-2\right)^{2}\right\}}{\left(\theta^{2}\right\}} \\
& \times\left\{\theta\left(\theta^{2}-2\right)\left[2\left(\theta^{2}-2\right)^{2}-\theta^{2}\right]\left\{8\left(\theta^{2}-2\right)^{3}-12\left(\theta^{2}-2\right)^{2}-3 \theta^{2}\left(\theta^{2}-2\right)+4 \theta^{2}\right\} c_{1}\right. \\
& +(\theta+2)\left[2\left(\theta^{2}-2\right)-\theta\right]\left\{2\left[2\left(\theta^{2}-2\right)^{2}-\theta^{2}\right]-\theta\left(\theta^{2}-2\right)\right\} \\
& +2\left(\theta^{2}-2\right)\left[2\left(\theta^{2}-2\right)^{2}-\theta^{2}\right]\left[8\left(\theta^{2}-2\right)^{3}-3 \theta^{2}\left(\theta^{2}-1\right)\left(\theta^{2}-2\right)+\theta^{4}\right] c_{2} \\
& \left.+\left\{4\left(\theta^{2}-3\right)\left[2\left(\theta^{2}-2\right)^{2}-\theta^{2}\right]-4\left(\theta^{2}-2\right)^{2}+\theta^{2}\left(\theta^{2}-2\right)\right\}\right\}
\end{aligned}
$$

Proof: Phase 3: Two retailers determine their respective retail prices by maximizing their profit function. According to the profit function $\left(a_{1}\right)$ and the profit maximization condition $\frac{\partial \pi_{R_{i}}^{(1,1)}}{\partial p_{R_{i}}^{(1,1)}}=0, i=1,2$. of the two retailers, the equilibrium solution of the retail price of the two supply chain products is solved:

$$
p_{R_{i}}^{(1,1)}=\frac{2 p_{M_{i}}^{(1,1)}+\theta p_{M_{3-i}}^{(1,1)}+\theta+2}{4-\theta^{2}}, i=1,2 .
$$

The second stage: The equilibrium function of the retail price is substituted into the profit function $\left(b_{1}\right)$ of the two manufacturers:

$$
\pi_{M_{i}}^{(1,1)}=\left(p_{M_{i}}^{(1,1)}-p_{S_{i}}^{(1,1)}\right) \frac{\left(\theta^{2}-2\right) p_{M_{i}}^{(1,1)}+\theta p_{M_{3-i}}^{(1,1)}+\theta+2}{4-\theta^{2}}, i=1,2 .
$$


Two manufacturers' companies determine their respective wholesale prices by maximizing their profit function. Solve the equilibrium solution of the wholesale price of the product according to the profit function (2) of the two manufacturers and the profit maximization condition $\frac{\partial \pi_{M_{i}}^{(1,1)}}{\partial p_{M_{i}}^{(1,1)}}=0, i=1,2$ :

$$
\begin{aligned}
p_{M_{i}}^{(1,1)}= & \frac{1}{4\left(\theta^{2}-2\right)^{2}-\theta^{2}}\left\{2\left(\theta^{2}-2\right)^{2} p_{S_{i}}^{(1,1)}-\theta\left(\theta^{2}-2\right) p_{S_{3-i}}^{(1,1)}\right. \\
& \left.-(\theta+2)\left[2\left(\theta^{2}-2\right)-\theta\right]\right\}, i=1,2 .
\end{aligned}
$$

The first stage: Two supplier companies determine their respective supply prices by maximizing their profit function. Similarly, by substituting the equilibrium solution of the wholesale price into the profit function $\left(c_{1}\right)$ of the two supplier companies, you can get:

$$
\begin{aligned}
\pi_{S_{i}}^{(1,1)}= & \left(p_{S_{i}}^{(1,1)}-c_{i}\right)\left(\theta^{2}-2\right) \frac{1}{\left(4-\theta^{2}\right)\left[4\left(\theta^{2}-2\right)^{2}-\theta^{2}\right.}\left\{\left[2\left(\theta^{2}-2\right)^{2}-\theta^{2}\right] p_{S_{i}}^{(1,1)}\right. \\
& \left.+\theta\left(\theta^{2}-2\right) p_{S_{3-i}}^{(1,1)}+(\theta+2)\left[2\left(\theta^{2}-2\right)-\theta\right]\right\}, i=1,2 .
\end{aligned}
$$

Solve the equilibrium solution that the supplier sells to the manufacturer based on $\left(4_{1}\right)$ and profit maximization condition $\frac{\partial \pi_{S_{i}}^{(1,1)}}{\partial p}=0, i=1,2$ :

$$
\begin{aligned}
& p_{S_{i}}^{(1,1)}=\frac{1}{4\left[2\left(\theta^{2}-2\right)^{2}-\theta^{2}\right]^{2}-\theta^{2}\left(\theta^{2}-2\right)^{2}} \\
& \times\left\{-\theta^{2}\left(\theta^{2}-2\right)\left[2\left(\theta^{2}-2\right)^{2}-\theta^{2}\right] c_{3-i}+\left[2\left(\theta^{2}-2\right)^{2}-\theta^{2}\right]^{2} c_{i}\right. \\
& +(\theta+2)\left[2\left(\theta^{2}-2\right)-\theta\right]\left\{\theta\left(\theta^{2}-2\right)-2\left[2\left(\theta^{2}-2\right)^{2}-\theta^{2}\right]\right\}, i=1,2 .
\end{aligned}
$$

Bringing $p_{S_{i}}^{(1,1)}$ into (3) $)_{1}$ and (1) $)_{1}$ in turn, you can get the equilibrium solution of the retailer, and the theorem is proved.

Case 2: The profit function of the supply chain system under the $(1,2)$ decision can be expressed as:

$$
\begin{gathered}
\pi_{R_{i}}^{(1,2)}=\left(p_{R_{i}}^{(1,2)}-p_{M_{i}}^{(1,2)}\right)\left(1-p_{R_{i}}^{(1,2)}+\theta p_{R_{3-i}}^{(1,2)}\right), i=1,2 . \\
\pi_{M_{1}}^{(1,2)}=\left(p_{M_{1}}^{(1,2)}-p_{S_{1}}^{(1,2)}\right)\left(q_{1}^{(1,2)}\left(p_{R_{i}}^{(1,2)}\right)\right), i=1,2 . \\
\pi_{M_{2}}^{(1,2)}=\left(p_{M_{2}}^{(1,2)}-c_{2}\right)\left(q_{2}^{(1,2)}\left(p_{R_{i}}^{(1,2)}\right)\right), i=1,2 . \\
\pi_{S_{1}}^{(1,2)}=\left(p_{S_{1}}^{(1,2)}-c_{1}\right)\left(q_{1}^{(1,2)}\left(p_{M_{i}}^{(1,2)}\right)\right), i=1,2 .
\end{gathered}
$$

Theorem 2: Under the combination of $(1,2)$, the retail price equilibrium solutions of the two supply chains are: 


$$
\begin{aligned}
& p_{R_{1}}^{(1,2)}=\frac{1}{2\left(4-\theta^{2}\right)\left[\theta^{2}-2\left(\theta^{2}-2\right)^{2}\right]\left[\theta^{2}-4\left(\theta^{2}-2\right)^{2}\right]} \\
& \times\left\{\left(\theta^{2}-2\right)\left(8-3 \theta^{2}\right)\left[\theta^{2}-2\left(\theta^{2}-2\right)^{2}\right] c_{1}\right. \\
& +\theta\left(\theta^{2}-2\right)\left\{\left(\theta^{2}-2\right)\left(8-3 \theta^{2}\right)+4\left(3-\theta^{2}\right)\left[\theta^{2}-2\left(\theta^{2}-2\right)^{2}\right]\right\} c_{2} \\
& \left.+(\theta+2)\left[2\left(\theta^{2}-2\right)-\theta\right]\left\{\left(\theta^{2}-2\right)\left(8-3 \theta^{2}\right)+4\left(3-\theta^{2}\right)\left[\theta^{2}-2\left(\theta^{2}-2\right)^{2}\right]\right\}\right\} \\
& \quad p_{R_{2}}^{(1,2)}=\frac{\left(4-\theta^{2}\right)\left[\theta^{2}-2\left(\theta^{2}-2\right)^{2}\right]\left[\theta^{2}-4\left(\theta^{2}-2\right)^{2}\right]}{\quad} \\
& \quad\left\{\theta\left(\theta^{2}-2\right)\left(3-\theta^{2}\right)\left[\theta^{2}-2\left(\theta^{2}-2\right)^{2}\right] c_{1}\right. \\
& +\left(\theta^{2}-2\right)\left\{\theta^{2}\left(\theta^{2}-2\right)\left(3-\theta^{2}\right)+\left(8-3 \theta^{2}\right)\left[\theta^{2}-2\left(\theta^{2}-2\right)^{2}\right]\right\} c_{2} \\
& \left.+(\theta+2)\left(3-\theta^{2}\right)\left[2\left(\theta^{2}-2\right)-\theta\right]\left\{\theta\left(\theta^{2}-2\right)+2\left[\theta^{2}-2\left(\theta^{2}-2\right)^{2}\right]\right\}\right\}
\end{aligned}
$$

Proof: The third stage: Proof of the same theorem.

The second stage: The manufacturer of supply chain one aims to maximize its profit function, while the supply chain 2 aims to maximize the overall profit of suppliers and manufacturers, and determine the wholesale price of the two supply chains. Substituting the equilibrium solution of the retail price into A, B, two profit functions are available:

$$
\begin{gathered}
\pi_{M_{1}}^{(1,2)}=\left(p_{M_{1}}^{(1,2)}-p_{S_{1}}^{(1,2)}\right) \frac{\left(\theta^{2}-2\right) p_{M_{1}}^{(1,2)}+\theta p_{M_{2}}^{(1,1)}+\theta+2}{4-\theta^{2}} \\
\pi_{M_{2}}^{(1,2)}+\pi_{S_{2}}^{(1,2)}=\left(p_{M_{1}}^{(1,2)}-c_{2}\right) \frac{\left(\theta^{2}-2\right) p_{M_{2}}^{(1,2)}+\theta p_{M_{1}}^{(1,1)}+\theta+2}{4-\theta^{2}}
\end{gathered}
$$

According to the profit function $(1)_{2},(2)_{2}$ and the maximum profit condition $\frac{\partial \pi_{M_{1}}^{(1,2)}}{\partial p_{M_{1}}^{(1,2)}}=0, \frac{\partial \pi_{M_{2}}^{(1,2)}+\partial \pi_{S_{2}}^{(1,2)}}{\partial p_{M_{2}}^{(1,2)}}=0$, the equilibrium solution expression of the wholesale price of the two supply chain products can be solved:

$$
\begin{aligned}
& p_{M_{1}}^{(1,2)}=\frac{-2\left(\theta^{2}-2\right)^{2} p_{S_{1}}^{(1,2)}+\theta\left(\theta^{2}-2\right) c_{2}+(\theta+2)\left[2\left(\theta^{2}-2\right)-\theta\right]}{\theta^{2}-4\left(\theta^{2}-2\right)^{2}} \\
& p_{M_{2}}^{(1,2)}=\frac{\theta\left(\theta^{2}-2\right) p_{S_{1}}^{(1,2)}-2\left(\theta^{2}-2\right)^{2} c_{2}+(\theta+2)\left[2\left(\theta^{2}-2\right)-\theta\right]}{\theta^{2}-4\left(\theta^{2}-2\right)^{2}}
\end{aligned}
$$

The first stage: The supplier of supply chain one determines the pricing sold to the manufacturer by maximizing its profit function. Similarly, the profit function of the supplier that substitutes the equilibrium solution of the wholesale price into the supply chain one can be obtained: 


$$
\pi_{S_{1}}^{(1,2)}=\left(p_{S_{1}}^{(1,2)}-c_{1}\right)\left(\theta^{2}-2\right) \frac{\left[\theta^{2}-2\left(\theta^{2}-2\right)^{2}\right] p_{S_{1}}^{(1,2)}-\theta\left(\theta^{2}-2\right) c_{2}-(\theta+2)\left[2\left(\theta^{2}-2\right)-\theta\right]}{\left(4-\theta^{2}\right)\left[\theta^{2}-4\left(\theta^{2}-2\right)^{2}\right]}(5)_{2}
$$

$\frac{\partial \pi_{S_{1}}^{(1,2)}}{\partial p_{S_{1}}^{(1,2)}}=0$, solve the equilibrium solution that the supplier sells to the manufacturer's pricing:

$$
p_{S_{1}}^{(1,2)}=\frac{\left[\theta^{2}-2\left(\theta^{2}-2\right)^{2}\right] c_{1}+\theta\left(\theta^{2}-2\right) c_{2}+(\theta+2)\left[2\left(\theta^{2}-2\right)-\theta\right]}{2\left[\theta^{2}-2\left(\theta^{2}-2\right)^{2}\right]}
$$

Substituting $(6)_{2}$ into $(4)_{2}$ and $(3)_{2}$ and substituting into (1) $)_{2}$, solves the equilibrium solution of the available retail price, and theorem 2 is proved.

Scenario 3: The profit function of the supply chain system under the $(1,3)$ decision can be expressed as:

$$
\begin{gathered}
\pi_{R_{1}}^{(1,3)}=\left(p_{R_{1}}^{(1,3)}-p_{M_{1}}^{(1,3)}\right)\left(1-p_{R_{1}}^{(1,3)}+\theta p_{R_{2}}^{(1,3)}\right) \\
\pi_{R_{2}}^{(1,3)}+\pi_{M_{2}}^{(1,3)}=\left(p_{R_{2}}^{(1,3)}-p_{S_{2}}^{(1,3)}\right)\left(1-p_{R_{2}}^{(1,3)}+\theta p_{R_{1}}^{(1,3)}\right) \\
\pi_{M_{1}}^{(1,3)}=\left(p_{M_{1}}^{(1,3)}-p_{S_{1}}^{(1,3)}\right) q_{1}\left(p_{R_{1}}^{(1,3)}\right) \\
\pi_{S_{1}}^{(1,3)}=\left(p_{S_{1}}^{(1,3)}-c_{1}\right) q_{1}\left(p_{M_{1}}^{(1,3)}\right) \\
\pi_{S_{2}}^{(1,3)}=\left(p_{S_{2}}^{(1,3)}-c_{2}\right) q_{2}\left(p_{R_{2}}^{(1,3)}\right)
\end{gathered}
$$

Theorem 3: Under the $(1,3)$ combination, the retail price equilibrium solutions of the two supply chains are:

$$
\begin{aligned}
& p_{R_{1}}^{(1,3)}=\frac{1}{2\left(2-\theta^{2}\right)\left(4-\theta^{2}\right)\left\{\theta^{2}-4\left[2\left(\theta^{2}-2\right)^{2}-\theta^{2}\right]\right\}} \\
& \times\left\{2\left(\theta^{2}-2\right)\left[4\left(\theta^{2}-2\right)^{2}-\theta^{2}-\theta^{2}\left(\theta^{2}-2\right)\right] c_{1}\right. \\
& +2 \theta\left(2 \theta^{2}-7\right)\left[2\left(\theta^{2}-2\right)^{2}-\theta^{2}\right] c_{2} \\
& \left.+2(\theta+2)\left(7-2 \theta^{2}\right)\left[2 \theta\left(\theta^{2}-2\right)-4\left(\theta^{2}-2\right)^{2}+\theta^{2}\right]\right\} \\
& p_{R_{2}}^{(1,3)}=\frac{1}{2\left(2-\theta^{2}\right)\left(4-\theta^{2}\right)\left\{\theta^{2}-4\left[2\left(\theta^{2}-2\right)^{2}-\theta^{2}\right]\right\}} \\
& \times\left\{\theta\left(\theta^{2}-2\right)\left[4\left(\theta^{2}-2\right)^{2}-\theta^{2}-4\left(\theta^{2}-2\right)\right] c_{1}\right. \\
& +\left(5 \theta^{2}-16\right)\left[2\left(\theta^{2}-2\right)^{2}-\theta^{2}\right] c_{2}+(\theta+2)\left[16\left(\theta^{2}-2\right)^{3}\right. \\
& \left.\left.-12 \theta\left(\theta^{2}-2\right)^{2}-16\left(\theta^{2}-2\right)^{2}-4 \theta^{2}\left(\theta^{2}-2\right)+12 \theta\left(\theta^{2}-2\right)+3 \theta^{3}\right]\right\}
\end{aligned}
$$

Proof: Phase 3: Supply chain one retailer companies aim to maximize their 
profit function, while supply chain 2 aims to maximize the overall profit of manufacturers and retailers, and determine the retail price of the two supply chains. According to the two profit functions $\left(a_{3}\right),\left(b_{3}\right)$ and the maximum profit condition

$$
\frac{\partial \pi_{R_{1}}^{(1,3)}}{\partial p_{R_{1}}^{(1,3)}}=0, \frac{\partial \pi_{R_{2}}^{(1,3)}+\partial \pi_{M_{2}}^{(1,3)}}{\partial p_{R_{2}}^{(1,3)}}=0 \text {, the equilibrium solution of the retail price of }
$$
the two supply chain products is solved:

$$
\begin{aligned}
& p_{R_{1}}^{(1,3)}=\frac{2 p_{M_{1}}^{(1,3)}+\theta p_{S_{2}}^{(1,3)}+(\theta+2)}{4-\theta^{2}} \\
& p_{R_{2}}^{(1,3)}=\frac{\theta p_{M_{1}}^{(1,3)}+2 p_{S_{2}}^{(1,3)}+(\theta+2)}{4-\theta^{2}}
\end{aligned}
$$

The second stage: The manufacturer of supply chain one determines the wholesale price by maximizing its profit function. Substituting the equilibrium solution of the retail price into A can be obtained:

$$
\pi_{M_{1}}^{(1,3)}=\left(p_{M_{1}}^{(1,3)}-p_{S_{1}}^{(1,3)}\right) \frac{\left(\theta^{2}-2\right) p_{M_{1}}^{(1,3)}+\theta p_{S_{2}}^{(1,3)}+(\theta+2)}{4-\theta^{2}}
$$

According to the profit function $(3)_{3}$ and the maximum profit condition $\frac{\partial \pi_{M_{1}}^{(1,3)}}{\partial p_{M_{1}}^{(1,3)}}=0$, the equilibrium solution expression of the wholesale price of the supply chain can be solved:

$$
p_{M_{1}}^{(1,3)}=\frac{\left(\theta^{2}-2\right) p_{S_{1}}^{(1,3)}-\theta p_{S_{2}}^{(1,3)}-(\theta+2)}{2\left(\theta^{2}-2\right)}
$$

Phase 1: Two-supplier companies determine the pricing they sell to manufacturers by maximizing their profit function. Similarly, the equilibrium solution of the wholesale price is substituted into the profit function A, B of the two supplier companies, which can be obtained:

$$
\begin{gathered}
\pi_{S_{1}}^{(1,3)}=\left(p_{S_{1}}^{(1,3)}-c_{1}\right) \frac{\left(\theta^{2}-2\right) p_{S_{1}}^{(1,3)}+\theta p_{S_{2}}^{(1,3)}+(\theta+2)}{2\left(4-\theta^{2}\right)} \\
\pi_{S_{2}}^{(1,3)}=\left(p_{S_{2}}^{(1,3)}-c_{2}\right) \frac{\theta\left(\theta^{2}-2\right) p_{S_{1}}^{(1,3)}+\left[2\left(\theta^{2}-2\right)^{2}-\theta^{2}\right] p_{S_{2}}^{(1,3)}+(\theta+2)\left[2\left(\theta^{2}-2\right)-\theta\right]}{2\left(\theta^{2}-2\right)\left(4-\theta^{2}\right)}(6)_{3}
\end{gathered}
$$

According to the profit function $(5)_{3},(6)_{3}$ of the supplier company and the profit maximization condition $\frac{\partial \pi_{S_{1}}^{(1,3)}}{\partial p_{S_{1}}^{(1,3)}}=0, \frac{\partial \pi_{S_{2}}^{(1,3)}}{\partial p_{S_{2}}^{(1,3)}}=0$, solve the equilibrium solution that the supplier sells to the manufacturer's pricing:

$$
p_{S_{1}}^{(1,3)}=\frac{4\left(\theta^{2}-2\right)\left[2\left(\theta^{2}-2\right)^{2}-\theta^{2}\right] c_{1}-2 \theta\left[2\left(\theta^{2}-2\right)-\theta\right] c_{2}+2(\theta+2)\left[2 \theta\left(\theta^{2}-2\right)-4\left(\theta^{2}-2\right)^{2}+\theta^{2}\right]}{2\left(2-\theta^{2}\right)\left\{\theta^{2}-4\left[2\left(\theta^{2}-2\right)^{2}-\theta^{2}\right]\right\}}(7)_{3}
$$




$$
\begin{aligned}
p_{S_{2}}^{(1,3)}= & \frac{1}{\left\{\theta^{2}-4\left[2\left(\theta^{2}-2\right)^{2}-\theta^{2}\right]\right\}}\left\{\theta\left(\theta^{2}-2\right) c_{1}-2\left[2\left(\theta^{2}-2\right)^{2}-\theta^{2}\right] c_{2}\right. \\
& \left.+(\theta+2)\left[4\left(\theta^{2}-2\right)-3 \theta\right]\right\}
\end{aligned}
$$

Substituting $(7)_{3}$ and $(8)_{3}$ into $(4)_{3}$ and substituting into $(1)_{3},(2)_{3}$, and solving the equilibrium solution of the available retail price, the theorem is proved.

Scenario 4: Under the $(1,4)$ combination, the equilibrium solutions of the two supply chain retail prices are:

$$
\begin{aligned}
p_{R_{1}}^{(1,4)}=\frac{1}{2\left(2-\theta^{2}\right)\left(4-\theta^{2}\right)}\left\{\left(2-\theta^{2}\right) c_{1}+\theta\left(7-2 \theta^{2}\right) c_{2}+(\theta+2)\left(7-2 \theta^{2}\right)\right\} \\
p_{R_{2}}^{(1,4)}=\frac{1}{4\left(2-\theta^{2}\right)\left(4-\theta^{2}\right)}\left\{\theta\left(2-\theta^{2}\right) c_{1}+\left(16-5 \theta^{2}\right) c_{2}\right. \\
\left.\quad+(\theta+2)\left[4\left(2-\theta^{2}\right)+3 \theta\right]\right\}
\end{aligned}
$$

Scenario 5: Under the $(2,2)$ combination, the equilibrium solutions of the two supply chain retail prices are:

$$
\begin{aligned}
p_{R_{1}}^{(2,2)}= & \frac{1}{\left(4-\theta^{2}\right)\left\{\theta^{2}-4\left(\theta^{2}-2\right)^{2}\right\}}\left\{\left(\theta^{2}-2\right)\left(8-3 \theta^{2}\right) c_{1}\right. \\
& \left.+2 \theta\left(\theta^{2}-2\right)\left(3-\theta^{2}\right) c_{2}+2(\theta+2)\left(3-\theta^{2}\right)\left[2\left(\theta^{2}-2\right)-\theta^{2}\right]\right\} \\
p_{R_{2}}^{(2,2)}= & \frac{1}{\left(4-\theta^{2}\right)\left\{\theta^{2}-4\left(\theta^{2}-2\right)^{2}\right\}}\left\{2 \theta\left(\theta^{2}-2\right)\left(3-\theta^{2}\right) c_{1}\right. \\
& \left.+\left(\theta^{2}-2\right)\left(8-3 \theta^{2}\right) c_{2}+2(\theta+2)\left(3-\theta^{2}\right)\left[2\left(\theta^{2}-2\right)-\theta^{2}\right]\right\}
\end{aligned}
$$

Scenario 6: Under the $(2,3)$ combination, the equilibrium solutions of the two supply chain retail prices are:

$$
\begin{aligned}
& p_{R_{1}}^{(2,3)}=\frac{1}{2\left(2-\theta^{2}\right)\left(4-\theta^{2}\right)\left\{2\left(2-\theta^{2}\right)^{2}-\theta^{2}\right\}} \\
& \times\left\{\left(2-\theta^{2}\right)\left[\left(2-\theta^{2}\right)\left(8-3 \theta^{2}\right)-\theta^{2}\right] c_{1}+\theta\left(3-\theta^{2}\right)\left[2\left(2-\theta^{2}\right)^{2}-\theta^{2}\right] c_{2} \quad\left(\mathrm{a}_{6}\right)\right. \\
& \left.+(\theta+2)\left(3-\theta^{2}\right)\left[2\left(\theta^{2}-2\right)\left(2 \theta^{2}-\theta-4\right)-\theta^{2}\right]\right\} \\
& p_{R_{2}}^{(2,3)} \frac{1}{4\left(2-\theta^{2}\right)\left(4-\theta^{2}\right)\left\{2\left(2-\theta^{2}\right)^{2}-\theta^{2}\right\}} \\
& \times\left\{\theta\left(2-\theta^{2}\right)\left[4\left(2-\theta^{2}\right)\left(3-\theta^{2}\right)-\theta^{2}\right] c_{1}+\left(8-3 \theta^{2}\right)\left[2\left(2-\theta^{2}\right)^{2}-\theta^{2}\right] c_{2} \quad\left(\mathrm{~b}_{6}\right)\right. \\
& \left.+(\theta+2)\left[2\left(2-\theta^{2}\right)+\theta\right]\left[4\left(2-\theta^{2}\right)\left(3-\theta^{2}\right)-\theta^{2}\right]\right\}
\end{aligned}
$$

Scenario 7: Under the $(2,4)$ combination, the equilibrium solutions of the two supply chain retail prices are: 


$$
\begin{gathered}
p_{R_{1}}^{(2,4)}=\frac{1}{\left(2-\theta^{2}\right)\left(4-\theta^{2}\right)}\left[\left(2-\theta^{2}\right) c_{1}+\theta\left(3-\theta^{2}\right) c_{2}+(\theta+2)\left(3-\theta^{2}\right)\right] \\
p_{R_{2}}^{(2,4)}=\frac{1}{2\left(2-\theta^{2}\right)\left(4-\theta^{2}\right)}\left[\theta\left(2-\theta^{2}\right) c_{1}+\left(8-3 \theta^{2}\right) c_{2}+(\theta+2)\left(-2 \theta^{2}+\theta+4\right)\right]
\end{gathered}
$$

Scenario 8: Under the $(3,3)$ combination, the equilibrium solutions of the two supply chain retail prices are:

$$
\begin{aligned}
p_{R_{1}}^{(3,3)}= & \frac{1}{\left(4-\theta^{2}\right)\left[4\left(\theta^{2}-2\right)^{2}-\theta^{2}\right]}\left\{\left(\theta^{2}-2\right)\left(3 \theta^{2}-8\right) c_{1}\right. \\
& \left.+2 \theta\left(\theta^{2}-2\right)\left(\theta^{2}-3\right) c_{2}+2(\theta+2)\left(\theta^{2}-3\right)\left[2\left(\theta^{2}-2\right)-\theta\right]\right\} \\
p_{R_{2}}^{(3,3)}= & \frac{1}{\left(4-\theta^{2}\right)\left[4\left(\theta^{2}-2\right)^{2}-\theta^{2}\right]}\left\{2 \theta\left(\theta^{2}-2\right)\left(\theta^{2}-3\right) c_{1}\right. \\
& \left.+\left(\theta^{2}-2\right)\left(3 \theta^{2}-8\right) c_{2}+2(\theta+2)\left(\theta^{2}-3\right)\left[2\left(\theta^{2}-2\right)-\theta\right]\right\}
\end{aligned}
$$

Scenario 9: Under the $(3,4)$ combination, the equilibrium solutions of the two supply chain retail prices are:

$$
\begin{gathered}
p_{R_{1}}^{(3,4)}=\frac{1}{\left(\theta^{2}-2\right)\left(4-\theta^{2}\right)}\left\{\left(\theta^{2}-2\right) c_{1}+\theta\left(\theta^{2}-3\right) c_{2}+(\theta+2)\left(\theta^{2}-3\right)\right\} \\
p_{R_{2}}^{(3,4)}=\frac{1}{2\left(\theta^{2}-2\right)\left(4-\theta^{2}\right)}\left\{\theta\left(\theta^{2}-2\right) c_{1}+\left(3 \theta^{2}-8\right) c_{2}+(\theta+2)\left(2 \theta^{2}-\theta-4\right)\right\}
\end{gathered}
$$

Scenario 10: Under the $(4,4)$ combination, the equilibrium solutions of the two supply chain retail prices are:

$$
\begin{aligned}
& p_{R_{1}}^{(4,4)}=\frac{2 c_{1}+\theta c_{2}+\theta+2}{4-\theta^{2}} \\
& p_{R_{2}}^{(4,4)}=\frac{\theta c_{1}+2 c_{2}+\theta+2}{4-\theta^{2}}
\end{aligned}
$$

The proof of Case 4 to Case 10 is similar to Case 1 to Case 3 and is omitted here.

Considering the complexity of the model, this paper intends to analyze the equilibrium solution of the retail price of the two supply chains in the above ten cases through numerical experiments. In order to focus on the influence of key variables such as inter-chain substitutability, this paper assumes that the two supply chains have similarity, that is $c_{1}=c_{2}=5$, the inter-chain substitutability has a value range of $(0,1)$, and there are ten cases in total. In each case, there are two retail price equilibrium solutions. When the $c_{1}=c_{2}$ condition is satisfied, $(1,1),(2,2)$, the two retail price equilibrium solutions in the case of $(3,3),(4,4)$ are equal, so there are 16 equilibrium solutions after the merger (Figure 1 ).

Nature 1: When $\theta \rightarrow 0.8^{-}$, the equilibrium solution of the retail price of the two supply chains satisfies the condition of $p_{R_{1}}=p_{R_{2}} \rightarrow c_{1}=c_{2}$, the selling 


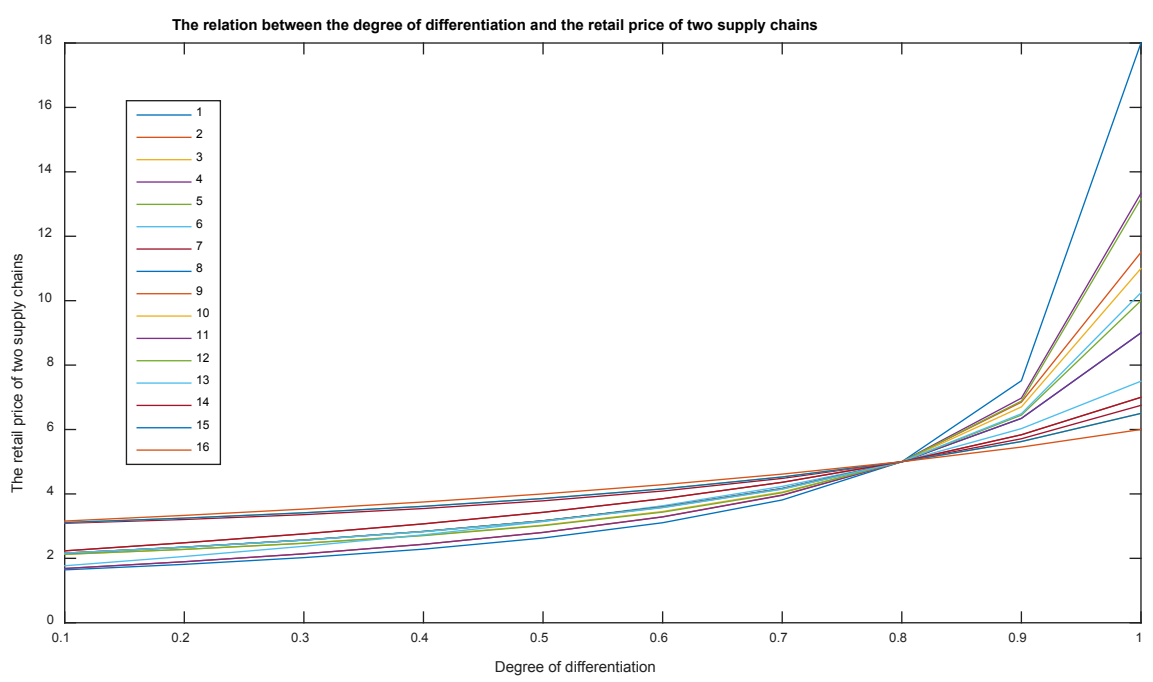

Figure 1. The ralation between the degree of differentiation and the retail price of two supply chains. Note: the line 1 to 16 indicated in the figure represents the final retail price of the two supply chains under the above ten decision forms; Respectively: $\left(d_{1}\right)\left(e_{2}\right)\left(f_{2}\right)$ $\left(f_{3}\right)\left(g_{3}\right)\left(a_{4}\right)\left(b_{4}\right)\left(a_{5}\right)\left(a_{6}\right)\left(b_{6}\right)\left(a_{7}\right)\left(b_{7}\right)\left(a_{8}\right)\left(a_{9}\right)\left(b_{9}\right)\left(a_{10}\right)$, when the two supply chains choose the same combination, the retail price of the two supply chains is equal, that is $\left(d_{1}\right)=\left(e_{1}\right), \quad\left(a_{5}\right)=\left(b_{5}\right), \quad\left(a_{8}\right)=\left(b_{8}\right), \quad\left(a_{10}\right)=\left(b_{10}\right)$.

price of the supply chain is close to the marginal cost, and the profit of the enterprise approaches zero. This is called "Bertrand Paradox".

The conclusion of the two three-level supply chain Bertrand equilibrium is that if the product differentiation of the two-chain production is small, close to 0.8 , then no supply chain can control the market price and obtain excess profits.

\section{Differentiated Models for Providing Value-Added Services}

In order to improve the phenomenon of low-price competition in the supply chain, it is necessary to expand the differentiation of products between the two supply chains. The following mainly studies the supply chain by providing value-added services to differentiate.

This paper assumes that product differentiation behavior in the supply chain refers to the cost of retailers in the supply chain to pay a certain value-added service. Assume that only the supply chain provides value-added services for product differentiation, $\Delta S$ represents the unit cost of the supply chain to provide value-added services, $\Delta v$ is a new service value of the supply chain, and after adding new variables, the supply chain is a retailer [8]. The profit function, supply chain one and supply chain two demand function are expressed as follows:

Then the demand function of supply chain 1 and supply chain 2 becomes:

$$
\begin{aligned}
& q_{1}=1-p_{R_{1}}+\theta\left(p_{R_{2}}+\Delta V\right) \\
& q_{2}=1-\left(p_{R_{2}}+\Delta V\right)+\theta p_{R_{1}}
\end{aligned}
$$


The profit function of a retail chain-retailer becomes:

$$
\pi_{R_{1}}=\left(p_{R_{1}}-p_{M_{1}}-\Delta S\right) q_{1}
$$

The following theorem gives the Bertrand game between two supply chains, the supply chain one provides product differentiation services, and the retail price changes of ten decision models.

Theorem 4.1: After the supply chain provides value-added services, the changes in retail prices are:

$$
\begin{aligned}
& \Delta p_{R_{1}}^{(1,1)}=\frac{1}{\left(4-\theta^{2}\right)\left[4\left(\theta^{2}-2\right)^{2}-\theta^{2}\right]\left\{4\left[2\left(\theta^{2}-2\right)^{2}-\theta^{2}\right]^{2}-\theta^{2}\left(\theta^{2}-2\right)^{2}\right\}} \\
& \times\left\{\theta\left(2-\theta^{2}\right)\left[2\left(\theta^{2}-2\right)^{2}-\theta^{2}\right]\right\}\left(2-\theta^{2}\right)\left(8-3 \theta^{2}\right) \\
& \left.+4\left(3-\theta^{2}\right)\left[2\left(\theta^{2}-2\right)^{2}-\theta^{2}\right]\right\} \Delta V+2\left(2-\theta^{2}\right)\left[2\left(\theta^{2}-2\right)^{2}-\theta^{2}\right] \\
& \left.\times\left\{\left(8-3 \theta^{2}\right)\left[2\left(\theta^{2}-2\right)^{2}-\theta^{2}\right]+\theta^{2}\left(2-\theta^{2}\right)\left(3-\theta^{2}\right)\right\} \Delta S\right\} \\
& \Delta p_{R_{1}}^{(\tilde{1}, 2)}=\frac{1}{2\left(4-\theta^{2}\right)\left[2\left(\theta^{2}-2\right)^{2}-\theta^{2}\right]\left[4\left(\theta^{2}-2\right)^{2}-\theta^{2}\right]} \\
& \times\left\{\theta\left(2-\theta^{2}\right)\left\{\left(2-\theta^{2}\right)\left(8-3 \theta^{2}\right)+4\left(3-\theta^{2}\right)\left[2\left(\theta^{2}-2\right)^{2}-\theta^{2}\right]\right\} \Delta V\right. \\
& \left.+\left(2-\theta^{2}\right)\left(8-3 \theta^{2}\right)\left[2\left(\theta^{2}-2\right)^{2}-\theta^{2}\right] \Delta S\right\} \\
& \Delta p_{R_{1}}^{\tilde{(1,3)}}=\frac{1}{\left(2-\theta^{2}\right)\left(4-\theta^{2}\right)\left\{4\left[2\left(\theta^{2}-2\right)^{2}-\theta^{2}\right]-\theta^{2}\right\}} \\
& \times\left\{\theta\left(7-2 \theta^{2}\right)\left[2\left(\theta^{2}-2\right)^{2}-\theta^{2}\right] \Delta V+\left(2-\theta^{2}\right)\left[\left(2-\theta^{2}\right)\left(8-3 \theta^{2}\right)-\theta^{2}\right] \Delta S\right\} \\
& \Delta p_{R_{1}}^{\tilde{(1,4)}}=\frac{1}{2\left(2-\theta^{2}\right)\left(4-\theta^{2}\right)}\left\{\theta\left(7-2 \theta^{2}\right) \Delta V+\left(2-\theta^{2}\right) \Delta S\right\} \\
& \Delta p_{R_{1}}^{\tilde{(1,5)}}=\frac{1}{\left(4-\theta^{2}\right)\left[4\left(\theta^{2}-2\right)^{2}-\theta^{2}\right]} \\
& \times\left\{2 \theta\left(2-\theta^{2}\right)\left(3-\theta^{2}\right) \Delta V+\left(2-\theta^{2}\right)\left(8-3 \theta^{2}\right) \Delta S\right\} \\
& \Delta p_{R_{1}}^{\tilde{(1,6)}}=\frac{1}{2\left(2-\theta^{2}\right)\left(4-\theta^{2}\right)\left[2\left(\theta^{2}-2\right)^{2}-\theta^{2}\right]} \\
& \times\left\{\theta\left(3-\theta^{2}\right)\left[2\left(\theta^{2}-2\right)^{2}-\theta^{2}\right] \Delta V\right. \\
& \left.+\left(2-\theta^{2}\right)\left\{\theta^{2}\left(3-\theta^{2}\right)+2\left[2\left(\theta^{2}-2\right)^{2}-\theta^{2}\right]\right\} \Delta S\right\}
\end{aligned}
$$




$$
\begin{gathered}
\Delta p_{R_{1}}^{\tilde{(1,7)}}=\frac{1}{\left(2-\theta^{2}\right)\left(4-\theta^{2}\right)}\left\{\theta\left(3-\theta^{2}\right) \Delta V+\left(2-\theta^{2}\right) \Delta S\right\} \\
\Delta p_{R_{1}}^{\tilde{(1,, 8)}}=\frac{1}{\left(4-\theta^{2}\right)\left[4\left(\theta^{2}-2\right)^{2}-\theta^{2}\right]} \\
\times\left\{2 \theta\left(2-\theta^{2}\right)\left(3-\theta^{2}\right) \Delta V+\left(2-\theta^{2}\right)\left(8-3 \theta^{2}\right) \Delta S\right\} \\
\Delta p_{R_{1}}^{(\tilde{1}, 9)}=\frac{1}{\left(2-\theta^{2}\right)\left(4-\theta^{2}\right)}\left\{\theta\left(3-\theta^{2}\right) \Delta V+\left(2-\theta^{2}\right) \Delta S\right\} \\
\Delta p_{R_{1}}^{(1,1,0)}=\frac{1}{4-\theta^{2}}(\theta \Delta V+2 \Delta S)
\end{gathered}
$$

Nature 2: By providing value-added services, the retail price increments in all ten forms of decision-making are positive.

Explain that the supply chain has increased the differentiation of products by providing value-added services, and increased the price of its own products, and when the decision forms of the two supply chains are $(2,2)$ and $(3,3)$ respectively, the supply chain one. The retail price increments are equal. When the decision forms of the two supply chains are $(2,4)$ and $(3,4)$, the retail price increments of supply chain one are also equal.

Theorem 4.2. From the perspective of input-output, to represent the efficiency of differentiation, the following are the differential investment cut-off points for ten decision models, They are represented by $e^{(1, i)}$ respectively, Among them, $i=1, \cdots, 10$.

$$
\begin{aligned}
& e^{(1,1)}=\frac{1}{\theta\left(2-\theta^{2}\right)\left[2\left(2-\theta^{2}\right)^{2}-\theta^{2}\right]\left\{\left(2-\theta^{2}\right)\left(8-3 \theta^{2}\right)+4\left(3-\theta^{2}\right)\left[2\left(2-\theta^{2}\right)^{2}-\theta^{2}\right]\right\}} \\
& \times\left\{\left(4-\theta^{2}\right)\left[4\left(2-\theta^{2}\right)^{2}-\theta^{2}\right]\left\{4\left[2\left(2-\theta^{2}\right)^{2}-\theta^{2}\right]^{2}-\theta^{2}\left(\theta^{2}-2\right)^{2}\right\}\right. \\
& \left.-2\left(2-\theta^{2}\right)\left[2\left(2-\theta^{2}\right)^{2}-\theta^{2}\right]\left[\left(8-3 \theta^{2}\right)\left[2\left(2-\theta^{2}\right)^{2}-\theta^{2}\right]+\theta^{2}\left(2-\theta^{2}\right)\left(3-\theta^{2}\right)\right\}\right\} \\
& e^{(1,2)}=\frac{1}{\theta\left(2-\theta^{2}\right)\left\{\left(2-\theta^{2}\right)\left(8-3 \theta^{2}\right)+4\left(3-\theta^{2}\right)\left[2\left(2-\theta^{2}\right)^{2}-\theta^{2}\right]\right\}} \\
& \times\left\{\left[2\left(2-\theta^{2}\right)^{2}-\theta^{2}\right]\left\{2\left(4-\theta^{2}\right)\left[4\left(2-\theta^{2}\right)^{2}-\theta^{2}\right]-\left(2-\theta^{2}\right)\left(8-3 \theta^{2}\right)\right\}\right\} \\
& e^{(1,3)}=\frac{1}{\theta\left(7-2 \theta^{2}\right)\left[2\left(2-\theta^{2}\right)^{2}-\theta^{2}\right]} \times\left\{( 2 - \theta ^ { 2 } ) \left\{4\left(4-\theta^{2}\right)\right.\right. \\
& \left.\left.\times\left[2\left(2-\theta^{2}\right)^{2}-\theta^{2}\right]-\theta^{2}\left(4-\theta^{2}\right)-\left(2-\theta^{2}\right)\left(8-3 \theta^{2}\right)+\theta^{2}\right\}\right\} \\
& e^{(1,4)}=\frac{2-\theta^{2}}{\theta}
\end{aligned}
$$




$$
\begin{gathered}
e^{(1,5)}=\frac{1}{2 \theta\left(2-\theta^{2}\right)\left(3-\theta^{2}\right)}\left\{\left(4-\theta^{2}\right)\left[4\left(2-\theta^{2}\right)^{2}-\theta^{2}\right]-\left(2-\theta^{2}\right)\left(8-3 \theta^{2}\right)\right\} \\
e^{(1,6)}=\frac{1}{\theta\left[2\left(2-\theta^{2}\right)^{2}-\theta^{2}\right]}\left\{2\left(2-\theta^{2}\right)\left[2\left(2-\theta^{2}\right)^{2}-\theta^{2}\right]-\theta^{2}\left(2-\theta^{2}\right)\right\} \\
e^{(1,8)}=\frac{1}{2 \theta\left(2-\theta^{2}\right)\left(3-\theta^{2}\right)}\left\{\left(4-\theta^{2}\right)\left[4\left(2-\theta^{2}\right)^{2}-\theta^{2}\right]-\left(2-\theta^{2}\right)\left(8-3 \theta^{2}\right)\right\} \\
e^{(1,9)}=\frac{2-\theta^{2}}{\theta} \\
e^{(1,10)}=\frac{2-\theta^{2}}{\theta}
\end{gathered}
$$

Proof: If $\Delta p-\Delta S<0$, although the differentiation increases the retail price of the supply chain, the increased profit is not enough to make up for the difference in the input, the supply chain losses; $\Delta p-\Delta S \geq 0$, indicates that differentiation brings value to the supply chain, and the supply chain is worthy of differentiation. $\Delta p$ is a function of $\Delta V$ and $\Delta S$, so according to $\Delta p-\Delta S=0$, it is easy to differentiate the expression of the investment demarcation point. And the differential critical points of the above ten decision situations can be summed up. Notes: Among them, $e^{(i, j)}$ represents the first supply chain to choose the $i=1,2,3,4$ combination form, and the second supply chain chooses the $j=1,2,3,4$ combination form.

$$
\begin{gathered}
e^{(1,1)}=\frac{1}{\theta\left(2-\theta^{2}\right)\left[2\left(2-\theta^{2}\right)^{2}-\theta^{2}\right]\left\{\left(2-\theta^{2}\right)\left(8-3 \theta^{2}\right)+4\left(3-\theta^{2}\right)\left[2\left(2-\theta^{2}\right)^{2}-\theta^{2}\right]\right\}} \\
\times\left\{\left(4-\theta^{2}\right)\left[4\left(2-\theta^{2}\right)^{2}-\theta^{2}\right]\left\{4\left[2\left(2-\theta^{2}\right)^{2}-\theta^{2}\right]^{2}-\theta^{2}\left(\theta^{2}-2\right)^{2}\right\}\right. \\
\left.-2\left(2-\theta^{2}\right)\left[2\left(2-\theta^{2}\right)^{2}-\theta^{2}\right]\left\{\left(8-3 \theta^{2}\right)\left[2\left(2-\theta^{2}\right)^{2}-\theta^{2}\right]+\theta^{2}\left(2-\theta^{2}\right)\left(3-\theta^{2}\right)\right\}\right\} \\
e^{(1,2)}=e^{(2,2)}=e^{(3,3)}=\frac{\left(4-\theta^{2}\right)\left[4\left(\theta^{2}-2\right)^{2}-\theta^{2}\right]-\left(2-\theta^{2}\right)\left(8-3 \theta^{2}\right)}{2 \theta\left(2-\theta^{2}\right)\left(3-\theta^{2}\right)} \\
e^{(1,3)}=e^{(2,3)}=\frac{\left(2-\theta^{2}\right)\left\{2\left[2\left(\theta^{2}-2\right)^{2}-\theta^{2}\right]-\theta^{2}\right\}}{\theta\left[2\left(\theta^{2}-2\right)^{2}-\theta^{2}\right]} \\
e^{(1,4)}=e^{(2,4)}=e^{(3,4)}=e^{(4,4)}=\frac{2-\theta^{2}}{\theta}
\end{gathered}
$$

Because the above results are quite complex, the following results are expressed in numerical simulation, and the inter-chain substitutability has a value range of $(0,1)$ (Figure 2$)$. 


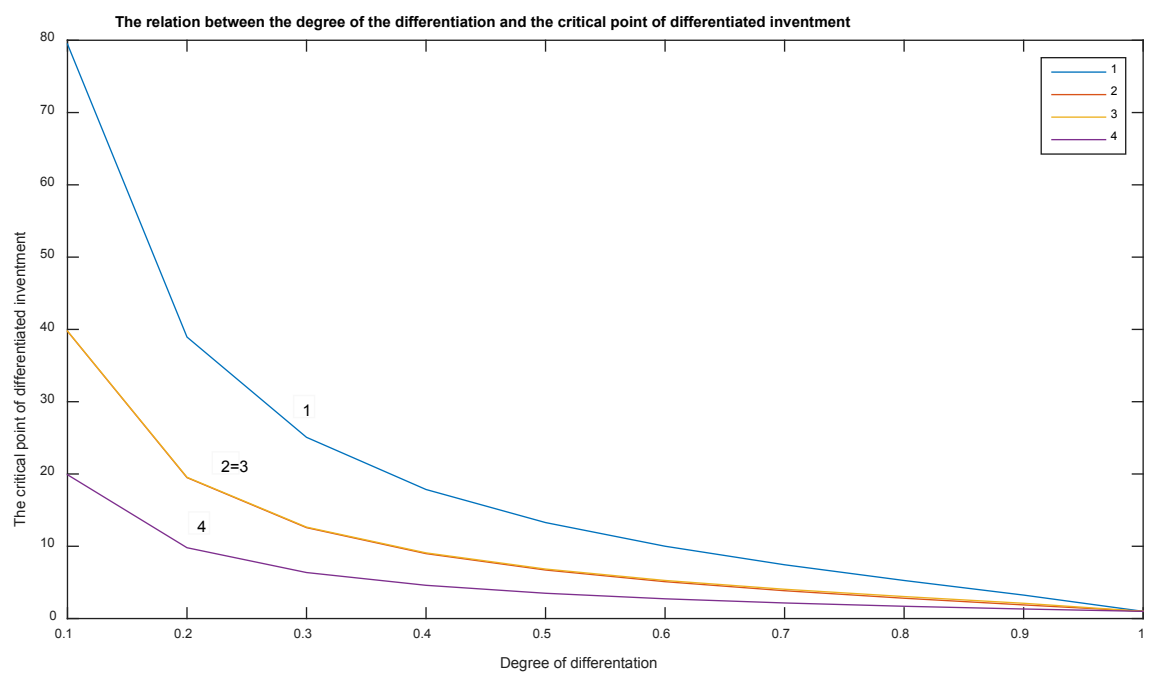

Figure 2. The relation between the degree of differentiation and the critical point of differentiated inventment. Note: in figure, where " 1 " means $e^{(1,1)}, " 2=3$ " means $e^{(1,2)}$ or $e^{(1,3)}$, because the calculated $e^{(1,2)}$ approximation is equal to $e^{(1,3)}$, so the line 2 is basically coincided with the line 3 , and " 4 " means $e^{(1,4)}$.

Theorem 4.3: It can be seen from figure that when the degree of differentiation is constant, the efficiency of differentiation under each decision form has the following relationship:

When the decision mode between supply chains is $(1,1)$, the relationship $e^{*(1)}=e^{(1,1)}$ can be obtained;

When the supply chain decision mode is $(1,3),(2,3)$, the relationship $e^{*(2)}=e^{(1,3)}=e^{(2,3)}$ can be obtained;

When the supply chain decision mode is $(1,2),(2,2),(3,3)$, the relationship $e^{*(3)}=e^{(1,2)}=e^{(2,2)}=e^{(3,3)}$ can be obtained; And when the degree of differentiation is small $(\theta \leq 0.3)$, the relationship $e^{*(2)}=e^{*(3)}$ can be obtained;

When the supply chain decision mode is $(1,4),(2,4),(3,4),(4,4)$, the relationship $e^{*(4)}=e^{(1,4)}=e^{(2,4)}=e^{(3,4)}=e^{(4,4)}$ can be obtained.

Analysis: Using the positive and negative of the difference in the efficiency of the investment efficiency in the above-mentioned properties, it is possible to judge whether or not to conduct differentiated investment behavior. When two supply chains select one of the ten decision-making forms, when the differentiation efficiency is controlled to be greater than the corresponding decision-critical point, $\Delta p-\Delta S \geq 0$ can be launched, and the price increment can make up for the difference. Investment, at this time, the supply chain will increase its own revenue by providing value-added services, and realize the differentiation of value-added services.

Nature 3: The efficiency of differentiation decreases as the degree of differentiation decreases. When $\theta<0.4$, the differentiation efficiency decreases rapidly with the decrease of the degree of differentiation, when $\theta>0.4$, the differentiation efficiency decreases slowly as the degree of differentiation decreases.

Nature 4: According to the above theorem, when $\mathrm{A}$ is certain, the dividing 
point of differentiation efficiency is $e^{*(1)}>e^{*(2)}>e^{*(3)}>e^{*(4)}$ from large to small; And approximately the following relationship: $e^{*(2)}=e^{*(3)}$.

Analysis: Because $e^{*(1)}>e^{*(2)}>e^{*(3)}>e^{*(4)}$, when $\theta$ is certain, the value of $e^{*(1)}$ is the largest. Therefore, the differentiation efficiency determined by the critical point of differentiated investment is the largest. Therefore, the differentiation efficiency determined by the critical point of differentiated investment is the largest. Therefore, among the ten types of decision-making, when the supply chain two chooses the decentralized decision-making, the value-added service brings the most differentiated efficiency to the supply chain, thereby maximizing the value-added, maximizing the differentiation of value-added services and decentralizing decision-making. It is also the optimal strategy of supply chain one; when $\theta$ is certain, the value of $e^{*(4)}$ is the smallest, so the differentiation efficiency determined by the critical point is also the smallest. Therefore, as long as the supply chain 2 adopts centralized decision-making, no matter which one of the supply chain adopts centralized decision-making, decentralized decision-making or partial centralized decision-making, the value-added service brings the least difference efficiency to the supply chain and the minimum value-added gain; When part of the centralized decision-making is made in the supply chain, the value-added services to the supply chain are nearly equal in value, and are between the above two situations.

Nature 5: According to Table 1, when the degree of product substitution is certain, the boundary point of differentiated investment has the following approximate relationship: $e^{*(1)}=2 e^{*(2)}=4 e^{*(3)}$.

When the degree of product differentiation is certain and relatively large, in the three-level supply chain bertrand game mode, there is an approximate proportional relationship between the values of the three different types of differential investment points, because when the differentiation efficiency is controlled

Table 1. Four kinds of differentiated investment critical points under different degree of differentiation(Note: $t$ indicates the degree of differentiation).

\begin{tabular}{ccccc}
\hline & Curve 1 & Curve 2 & Curve 3 & Curve 4 \\
\hline$t=0.1$ & 79.4743401 & 39.74974874 & 39.77484261 & 19.9 \\
$t=0.2$ & 38.94463095 & 19.49795918 & 19.54871258 & 9.8 \\
$t=0.4$ & 25.07301568 & 12.57626527 & 12.65381847 & 6.366666667 \\
$t=0.5$ & 17.85389116 & 8.982608696 & 9.088673766 & 4.6 \\
$t=0.6$ & 13.27963526 & 6.714285714 & 6.85106383 & 3.5 \\
$t=0.7$ & 10.00557884 & 5.100813008 & 5.270619488 & 2.733333333 \\
$t=0.8$ & 7.441726712 & 3.850709555 & 4.054593316 & 2.157142857 \\
$t=0.9$ & 5.267880876 & 2.811764706 & 3.044351464 & 1.7 \\
$t=1$ & 3.246662642 & 1.888141923 & 2.11482324 & 1.32222222 \\
& 1 & 1 & 1 & 1
\end{tabular}


at $\mathrm{A}$ within the scope, the differentiation of value-added services can be truly realized, so when the degree of differentiation is certain, the efficiency of differentiation within this range is twice the relationship between the two. The control range of the differentiation efficiency under the other nine decision models can be determined by the control range of the differentiation efficiency of one of the decision models.

\section{Conclusions}

In this paper, based on the game problem of price competition between three supply chains, ten different models of decision-making are established, and the reasons for low-price competition between the two supply chains are quantitatively analyzed. It is found that when the products provided by the two supply chains are replaceable. The degree is very large; the differentiation is very small; the customer has little choice for the product, and the price is the only measure for the consumer to purchase the product. The only balanced result of the game between the two supply chains is to choose the price reduction. On the basis of the original model, we added value-added services, increased the differentiation between the two supply chains, established a model for product differentiation in one supply chain, and quantitatively analyzed the differentiation to supply. The impact of chain-price indicates that the supply chain has improved product prices through product differentiation models based on value-added services, avoiding price vicious competition and reducing consumer price sensitivity. However, in order to make the product differentiation behavior of value-added services bring value to the supply chain, the differentiation efficiency must be controlled within a certain range; according to the numerical calculation, three different differential investment thresholds are obtained, thus obtaining three kinds of different differentiation efficiency control scope, under each decision condition; in order to obtain new revenue, the supply chain should control the product differentiation efficiency within the corresponding range; so according to the critical point value of the differential investment relationships, to compare the efficiency of differentiation, it is found that when supply chain two chooses decentralized decision-making, the differentiated behavior brings the greatest benefit to the supply chain. When the supply chain chooses centralized decision-making, the differentiated behavior is given to the supply chain. The added value of the benefits is minimal; when the two supply chains select part of the centralized decision-making, the differentiated behavior brings the benefit of the supply chain to the center. At the same time, when the degree of differentiation is certain, the three differentiationn efficiencies have a relationship between two and two. According to the differentiation efficiency of one of the decision forms, the differentiation efficiency of the remaining decision forms can be derived.

The main innovations of this paper are: First, for the Bertrand game between the two three level supply chains, we can provide value-added services to one of the supply chains and raise the price of products, so as to avoid price vicious 
competition. Second: according to each of the ten decision forms, one of the supply chains can identify the most favorable supply chain profit differentiation behavior through differential expression of the investment threshold. Third: from Figure 2, we can find that the supply chain with value-added services is dispersed when the degree of alienation is constant.

The shortcomings of this article: This article only studies one of the supply chain to provide value-added services to improve their retail prices, reduce the degree of differentiation, and bring about the increase of income, without studying the role of one supply chain in providing supply chain two by providing value-added services.

\section{Conflicts of Interest}

The authors declare no conflicts of interest regarding the publication of this paper.

\section{References}

[1] Lu, W.L., Chen, H.M. and Shuai, X. (2004) Entry Barriers and Firms' Product Differentiation Strategy. Journal of Industrial Engineering and Engineering Management, No. 3, 38-41.

[2] Gong, R.C. and Liu, L. (2011) Effect of Firm's Differentiation Strategy on Price and Quality Competition Game Equilibrium Solution. Economic Review, No. 1, 23-30.

[3] Li, B.X. (2013) Analysis of Bertrand Game Decision-Making between Multiple Supply Chains under Price and Service Competition. Jiangsu Commercial, No. 2, 20-23.

[4] Tan, Z.L. and Liang, Z.X. (2016) Research on Dynamic Repeated Game Model of China's Coal Market Price. Coal Economic Research, 36, 45-48.

[5] Peng, L., Zhang, B.X. and Chen, X.C. (2016) Pricing Policies for a Dual-Channel Supply Chain Under Service Level. Mathematic in Practice and Theory, 46, 98-106.

[6] Li, B.X., Nan, Y.R. and Guo, J. (2018) Channel Choice Strategy with Risk Aversion: Company-Owned Store vs Franchised Store. Mathematics in Practice and Theory, 48, 58-69.

[7] Zhang, B.X., Wang, W.L., Zhang, M.Z. and Yu, X.L. (2015) Analysis of Stackelberg Game between Three-Level Supply Chains. Mathematics in Practice and Theory, 45, 154-163.

[8] Yang, L., Li, B.Y. and Lan, W.G. (2010) Study on the Strategy of Product Based on Game Analysis. Management Review, 22, 62-67. 